\title{
Nitrate-responsive NarX-NarL represses arginine- mediated induction of the Pseudomonas aeruginosa arginine fermentation arcDABC operon
}

\section{Correspondence \\ Max Schobert \\ m.schobert@tu-bs.de}

Received 28 March 2008

Revised 11 June 2008

Accepted 18 June 2008

\author{
Beatrice Benkert, ${ }^{1}$ Nicole Quäck, ${ }_{1}^{1}$ Kerstin Schreiber, ${ }^{1} \dagger$ Lothar Jaensch, ${ }^{2}$ \\ Dieter Jahn ${ }^{1}$ and Max Schobert ${ }^{1}$
}

\author{
${ }^{1}$ Institute of Microbiology, Technical University Braunschweig, Spielmannstr. 7, D-38106 \\ Braunschweig, Germany \\ ${ }^{2}$ Division of Cell and Immune Biology, Proteome Research Group, Helmholtz Centre for Infection \\ Research, Inhoffenstr. 7, D-38124 Braunschweig, Germany
}

\begin{abstract}
Denitrification and arginine fermentation are major parts of the anaerobic metabolism of Pseudomonas aeruginosa, which is important for biofilm formation and infection. The twocomponent regulatory system NarX-NarL is part of the underlying network and is required for denitrifying growth. All target promoters identified so far are activated by NarL. In this study the effect of NarL on arginine fermentation was investigated using proteome, Northern blot and lac $Z$ reporter gene analyses. NarL-dependent repression of the $\operatorname{arc} D A B C$ operon was observed and the corresponding NarL-binding site in the $\operatorname{arc} D$ promoter region was functionally localized at -60 bp upstream of the transcriptional start site using site-directed promoter mutagenesis and reporter gene fusion experiments. The results clearly show that in the presence of nitrate NarL represses the arginine-dependent activation of the $\operatorname{arc} D A B C$ operon mediated by ArgR. It does not influence the oxygen-tension-dependent activation via Anr. Thus, the anaerobic energy metabolism of $P$. aeruginosa is coordinated via NarX-NarL activity. In the presence of nitrate the highly efficient denitrification is preferred over the less attractive arginine fermentation.
\end{abstract}

\section{INTRODUCTION}

In Pseudomonas aeruginosa anaerobic metabolism is important for biofilm growth and for the infection of the cystic fibrosis lung involving biofilm-like $P$. aeruginosa microcolonies (Barraud et al., 2006; Filiatrault et al., 2006; Hassett et al., 2002; Palmer et al., 2007; Platt et al., 2008; Sauer et al., 2002; Van Alst et al., 2007; Worlitzsch et al., 2002; Xu et al., 1998). In the absence of oxygen $P$. aeruginosa grows either by denitrification or by arginine fermentation (Carlson \& Ingraham, 1983; Vander Wauven et al., 1984; Zumft, 1997). The expression of genes which encode enzymes for denitrification in $P$. aeruginosa are controlled by the regulatory proteins Anr and Dnr, as well as the nitrate-responsive two-component system NarXNarL (Arai et al., 1997; Schreiber et al., 2007; Ye et al., 1995). Enzymes required for arginine fermentation are encoded by genes which are organized in the operon $\operatorname{arcDABC}$ (Luthi et al., 1990). Anaerobic expression of $\operatorname{arcDABC}$ has been shown to be Anr-dependent and further

tPresent address: Institute of Biochemistry and Biotechnology, Technical University Braunschweig, Spielmannstr. 7, D-38106 Braunschweig, Germany.

Abbreviations: MU, Miller units; RuBPS, ruthenium(II)-tris(bathophenanthroline disulfonate). stimulated by the arginine-responsive regulator $\operatorname{ArgR}(\mathrm{Lu}$ et al., 1999). The global oxygen-sensing regulator Anr is an Escherichia coli Fnr homologue and is essential for fermentative and denitrifying growth in the absence of oxygen (Ye et al., 1995). Moreover, Anr controls the expression of $d n r$, which encodes the nitrogen-oxidesensing regulator Dnr (Arai et al., 1997). Dnr finally induces expression of the genes encoding the nitrite, nitric oxide and nitrous oxide reductases required for denitrification (Arai et al., 1999, 2003). Mutant and gene expression studies in $P$. aeruginosa and Pseudomonas stutzeri showed that the two-component system NarXNarL is additionally required for denitrifying growth (Härtig et al., 1999; Schreiber et al., 2007). The $P$. aeruginosa NarX protein is a sensor kinase and shares $38 \%$ and $34 \%$ sequence identity with NarX from $P$. stutzeri and E. coli, respectively (Härtig et al., 1999). The NarL protein is the corresponding response regulator to NarX and shares amino acid identity of $63 \%$ and $58 \%$ with NarL from P. stutzeri and E. coli, respectively (Härtig et al., 1999). In addition to NarX-NarL, E. coli harbours a second two-component system named NarQ-NarP (Chiang et al., 1992; Rabin \& Stewart, 1993). However, so far no obvious narQ homologue has been functionally identified in the P. aeruginosa genome (Stewart, 2003). 
Recently, the NarL regulon of E. coli was reassessed in a comprehensive microarray experiment (Constantinidou et al., 2006). This approach revealed the activation of 51 operons and the repression of 41 operons by NarL. In E. coli the NarXNarL system is involved in the coordination of anaerobic energy metabolism by inducing nitrate respiration and repressing less efficient modes of energy metabolism including fermentation processes (Constantinidou et al., 2006; Stewart \& Rabin, 1995). In pseudomonads only a few genes have been experimentally confirmed to be targets of NarL activation. In $P$. stutzeri these are narG, narK and $d n r E$ and in $P$. aeruginosa hemA, narK, nirQ and dnr (Härtig et al., 1999; Krieger et al., 2002; Schreiber et al., 2007; Vollack et al., 1999). However, so far no gene has been shown to be repressed by NarL. The effect of NarL on the transcription of genes involved in other, less favourable energy-generating systems than denitrification is unknown. In this study we investigated the effect of NarL on arginine fermentation in more detail using a combination of 2D gel electrophoresis, Northern blot analysis and lacZ reporter gene fusion experiments.

\section{METHODS}

Bacterial strains, plasmids and media. The bacterial strains and plasmids used in this study are listed in Table 1. Bacteria were grown in LB medium (per litre: $10 \mathrm{~g}$ tryptone, $5 \mathrm{~g}$ yeast extract and $5 \mathrm{~g}$ $\mathrm{NaCl}$ ) or modified $\mathrm{AB}$ minimal medium (Heydorn et al., 2000; Schreiber et al., 2006) as indicated. For anaerobic growth $50 \mathrm{mM}$ $\mathrm{KNO}_{3}$ was added. If appropriate, the antibiotic tetracycline was added at final concentrations of $5 \mu \mathrm{g} \mathrm{ml}^{-1}$ for E. coli and $100 \mu \mathrm{g} \mathrm{ml}^{-1}$ for $P$. aeruginosa. All incubations were carried out at $37^{\circ} \mathrm{C}$.

Proteome analysis. $P$. aeruginosa cells were grown anaerobically in $\mathrm{LB}$ containing $50 \mathrm{mM} \mathrm{KNO}_{3}$. Cultures in the exponential growth phase were mixed with twice the volume of ice-cold potassium phosphate buffer (100 mM; pH 7.4) and allowed to cool for 5 min. Cells were centrifuged at $8000 \mathrm{~g}$ for $20 \mathrm{~min}$ at $4{ }^{\circ} \mathrm{C}$ and washed twice with potassium phosphate buffer. Sedimented $P$. aeruginosa cells were resuspended in a small volume of potassium phosphate buffer and protein isolation was done as described previously (Schreiber et al., 2006). The protein concentration was determined in sample buffer using the PlusOne 2D Quant kit (Amersham Biosciences). The 2D gel electrophoresis was performed using immobilized $\mathrm{pH}$ gradient (IPG) strips of $17 \mathrm{~cm}$ length covering the $\mathrm{pH}$ range 5-8 (Bio-Rad). The IPG strips were rehydrated overnight in rehydration buffer containing $500 \mu \mathrm{g}$ protein. Isoelectric focusing (IEF) was carried out at $20{ }^{\circ} \mathrm{C}$ under mineral oil in a PROTEAN IEF Cell (Bio-Rad) for a total of 110 $\mathrm{kV} \mathrm{h}$. The focused IPG strips were reduced for $15 \mathrm{~min}$ in an SDS equilibration solution containing $15 \mathrm{mM}$ DTT and afterwards alkylated twice for $15 \mathrm{~min}$ in the same buffer containing $150 \mathrm{mM}$ iodacetamide prior to SDS-PAGE. The IPG strips were transferred to $10 \%$ polyacrylamide gels $(25.5 \times 20.5 \mathrm{~cm})$. SDS-PAGE was performed at a constant temperature of $20{ }^{\circ} \mathrm{C}$ with $2 \mathrm{~W}$ per gel for approximately $20 \mathrm{~h}$. All gels were stained with ruthenium(II)tris(bathophenanthroline disulfonate) (RuBPS), as described before (Schreiber et al., 2006). Gels were documented with an FX-Scanner (Bio-Rad). Analysis and quantification of differential protein spot patterns was performed using the Software Z3 (Compugen). Two independent replicates were used for analysis. Proteins were identified by mass spectrometry as described previously (Schreiber et al., 2006).

Northern blot analysis. For RNA extraction, cells were grown under oxygen-limited conditions in LB medium at $37{ }^{\circ} \mathrm{C}$ to an $\mathrm{OD}_{578}$ of 0.2 . RNA was prepared as described by Boes et al. (2006). Ten micrograms of RNA was separated electrophoretically on a $1 \%$ agarose gel containing $5 \%$ formaldehyde and then transferred to a nylon membrane. For hybridization, a digoxigenin-labelled $\operatorname{arcA}$ probe was used and the typical $\operatorname{arc} A B C$, $\operatorname{arc} A B$ and $\operatorname{arc} A$ transcripts were detected (Gamper et al., 1992). The $\operatorname{arcA}$ probe was generated using the primer pair arcA-NO-for (5'-CTGACCGAGACCATCCAGAA-3') and arcA-NO-rev (5'-CTAATACGACTCACTATAGGGAGACAGCAGGGTGTTGGTGTAGG-3'). DNA was labelled using the Digoxigenin RNA Labelling kit (Roche). CDP-Star (NEB) was used for detection.

Table 1. Strains and plasmids used in this study

\begin{tabular}{|c|c|c|}
\hline $\begin{array}{l}\text { Bacterial strain or } \\
\text { plasmid }\end{array}$ & Genotype or phenotype & Reference \\
\hline \multicolumn{3}{|l|}{ P. aeruginosa } \\
\hline PAO1 & Wild-type & Dunn \& Holloway (1971) \\
\hline PAO9104 & narL: : cat, $\mathrm{Cm}^{\mathrm{R}}$ & Krieger et al. (2002) \\
\hline BB43 & PAO1 attB:: $\left(P_{\mathrm{arcD}}-l a c Z\right)$ & This work \\
\hline BB45 & PAO9104 attB:: $\left(P_{\mathrm{arcD}}-l a c Z\right)$ & This work \\
\hline BB46 & PAO1 attB: : ( $\left.P_{\text {arcD } \Delta N a r L}-l a c Z\right)$ & This work \\
\hline \multicolumn{3}{|c|}{ 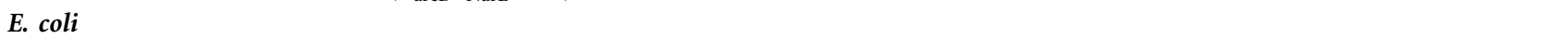 } \\
\hline DH10B & $\begin{array}{l}\mathrm{F}^{-} \text {mcrA } \Delta(m r r-h s d R M S-m c r B C) \phi 80 \mathrm{~d} l a c Z \Delta \mathrm{M} 15 \Delta \text { lacX74 deoR recA1 endA1 araD139 } \\
\Delta(\text { ara, leu }) 7697 \text { galU galK } \lambda^{-} \text {rpsL nupG }\end{array}$ & GibcoBRL (Invitrogen) \\
\hline S17 $\lambda$-pir & pro thi $h s d R^{+} \mathrm{Tp}^{\mathrm{r}} \mathrm{Sm}^{\mathrm{r}}$; chromosome::RP4-2 $\mathrm{Tc}:: \mathrm{Mu}-\mathrm{Km}:: \mathrm{Tn} 7 / \lambda$ pir & de Lorenzo \& Timmis (1994) \\
\hline SM10 & thi-1 thr leu tonA lacY supE recA:: RP4-2-Tc:: $\mathrm{Mu}\left(\mathrm{Km}^{\mathrm{R}}\right)$ & de Lorenzo \& Timmis (1994) \\
\hline \multicolumn{3}{|l|}{ Plasmids } \\
\hline mini-CTX-lacZ & $\mathrm{Tc}^{\mathrm{R}}$; promoterless lac $Z$ gene & Becher \& Schweizer (2000) \\
\hline pFLP2 & $\mathrm{Ap}^{\mathrm{R}}$; source of FLP recombinase & Hoang et al. (1998) \\
\hline pDH11 & $\begin{array}{l}\mathrm{Tc}^{\mathrm{R}} \text {; mini-CTX-lacZ containing a } 1005 \text { bp Pst } \mathrm{I}-\text { Bam HI fragment encoding the } \operatorname{arcD} \\
\text { promoter }\end{array}$ & Dana Heldt \\
\hline pBB20 & $\mathrm{Tc}^{\mathrm{R}}$; pDH11 with the mutated NarL-binding site & This work \\
\hline
\end{tabular}


Construction of chromosomal arcD promoter-lacZ reporter gene fusions and corresponding reporter gene assay. The complete $\operatorname{arcD}$ promoter region (Fig. 3) was fused to E. coli lacZ. A $1005 \mathrm{bp}$ PCR product was generated using the primer pair ArcDfor_A (5'-AACTGCAGGCTGCCGTGGCTCATGAT-3') and ArcDrev_B

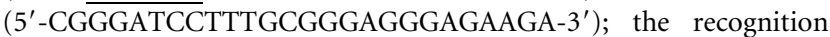
sequences for Pst I and BamHI are underlined. The resulting DNA fragment was digested with PstI and BamHI and cloned into the PstI/ BamHI-digested mini-CTX-lacZ vector to generate pDH11 (Table 1). This plasmid was integrated into the attB site of the $P$. aeruginosa $\mathrm{PAO} 1$ genome and the corresponding narL mutant strain to generate strains BB43 and BB45, respectively (Table 1). Transfer of plasmids into $P$. aeruginosa was carried out by a diparental mating as described before (Schreiber et al., 2006). In the mutant strains BB43, BB45 and BB46, parts of the mini-CTX-lacZ containing the tetracyclineresistance gene were deleted using a FLP recombinase encoded on the pFLP2 plasmid (Hoang et al., 1998). The $\beta$-galactosidase activities of the strains carrying lac $Z$ reporter gene fusions were determined in the early exponential phase at an $\mathrm{OD}_{578}$ of 0.2 and are given in Miller units (MU) (Schreiber et al., 2006). Data are the result of at least three independent experiments.

Mutation of the putative NarL-binding site. A potential NarLbinding site in the $\operatorname{arcD}$ promoter ( $\mathrm{pDH} 11$ ) was mutated using the crossover PCR technique (Ho et al., 1989). The putative binding motif in the $\operatorname{arcD}$ promoter region for the regulatory protein NarL was detected using the Virtual Footprint tool of the PRODORIC database (Münch et al., 2005). Mutation of the NarL box (TACTCAA $\rightarrow$ CATTCAA) was based on the published NarL consensus binding sequence (Tyson et al., 1993). The mutation was introduced using the primer pair oBB42 (5'-AATAGCTTCCCATTCAAAGTAATTAGAT-3') and oBB43 (5'-ATCTAATTACTTTGAATGGGAAGCTATT-3'; the mutated NarL-binding site is underlined) to generate pBB20. Nucleotide exchanges were verified by DNA sequence determination. The corresponding vector pBB20 was integrated into the attB site of the $P$. aeruginosa strain PAO1 chromosome to generate strain BB46 (Table 1).

\section{RESULTS}

\section{Proteome analysis of the narL mutant strain}

2D gel electrophoresis of water-soluble proteins was employed to monitor the NarL-dependent production of proteins in $P$. aeruginosa. We compared the protein patterns of the $P$. aeruginosa narL mutant PAO9104 with that of the wild-type PAO1. Seven proteins were found differentially synthesized in the narL mutant (Fig. 1, Table 2). We detected increased protein concentrations of $\mathrm{NarH}$ in wild-type cells. The NarH protein is the soluble, cytoplasmic subunit of the membrane-bound nitrate reductase, encoded by the narK $K_{1} K_{2} G H J I$ operon (Palmer et al., 2007; Schreiber et al., 2007; Sharma et al., 2006). This is in agreement with earlier investigations, which described that in $P$. aeruginosa and $P$. stutzeri the NarX-NarL twocomponent system activates transcription of the nitrate reductase operon (Härtig et al., 1999; Schreiber et al., 2007). The second protein found in increased concentrations in wild-type cells was porin E1 (OprE). The porin protein E1 gene oprE has been described before to be expressed in response to anaerobiosis (Yamano et al., 1993). Furthermore, the two-component class II ribonu- cleotide reductase subunits $\mathrm{NrdJa}$ and NrdJb showed an increased concentration in wild-type cells, suggesting a NarL-dependent induction of the corresponding genes (Torrents et al., 2005). Both proteins were recently found induced under anaerobic conditions in the presence of nitrate (Platt et al., 2008). Only three proteins with increased concentration in the narL mutant compared to PAO1 wild-type were found, suggesting a repression of the corresponding genes by NarL. MALDI-TOF analysis identified these proteins as arginine deiminase (ArcA), catabolic ornithine carbamoyltransferase $(\mathrm{ArcB})$ and carbamate kinase (ArcC) (Table 2). All three proteins are encoded by genes of the $\operatorname{arcDABC}$ operon and represent the arginine fermentation pathway for ATP generation.

\section{Northern blot analysis of the arcDABC mRNA}

No gene repression by NarL has previously been described for pseudomonads. Consequently, we focused our investigation on the observed decrease in ArcA, ArcB and ArcC protein concentration. In order to determine whether the regulation occurs on the mRNA or on the protein level, we performed Northern blot analyses using a digoxigeninlabelled $\operatorname{arc} A$ probe. The detection of three abundant transcripts, $\operatorname{arc} A B C$, $\operatorname{arc} A B$ and $\operatorname{arc} A$, has been described before (Gamper et al., 1992). First, we compared RNA levels prepared from $P$. aeruginosa wild-type cells grown under oxygen limitation in LB medium either with or without $50 \mathrm{mM}$ nitrate. Strong signals corresponding to the $\operatorname{arc} A B C, \operatorname{arc} A B$ and $\operatorname{arc} A$ transcripts were detected only for RNA prepared from wild-type cells grown without nitrate (see Fig. 2). We did not detect an $\operatorname{arcDABC}$ transcript. However, its low abundance was described before (Gamper et al., 1992). Interestingly, the probing of RNA prepared from the narL mutant strain PAO9104 grown with $50 \mathrm{mM}$ nitrate resulted in almost identical signal intensities. These results clearly indicate that NarL represses arginine fermentation on the transcriptional level.

\section{The arcDABC operon is repressed by NarL}

We used transcriptional $P_{\text {arcD-lac }} Z$ fusions to investigate the influence of NarL on the arcDABC promoter. We determined $\beta$-galactosidase activities of strains BB43 (wild-type) and BB45 (narL mutant) under identical conditions as described for the proteome analysis experiments. $\beta$-Galactosidase activities of $P_{\mathrm{arcD}}-l a c Z$ increased more than threefold in the narL mutant (BB45, $1975 \mathrm{MU}$ ) compared to the wild-type (BB43, $550 \mathrm{MU}$ ) under anaerobic conditions in the presence of nitrate. This observation suggests that the absence of the NarL regulator leads to an increased transcription of $\operatorname{arcD}$. Consequently, NarL is responsible for $\operatorname{arcDABC}$ repression.

\section{Identification of the NarL-binding site in the arcDABC promoter}

Next, we were interested to know if the observed decrease in the $\operatorname{arcDABC} \mathrm{mRNA}$ level and corresponding in vivo 

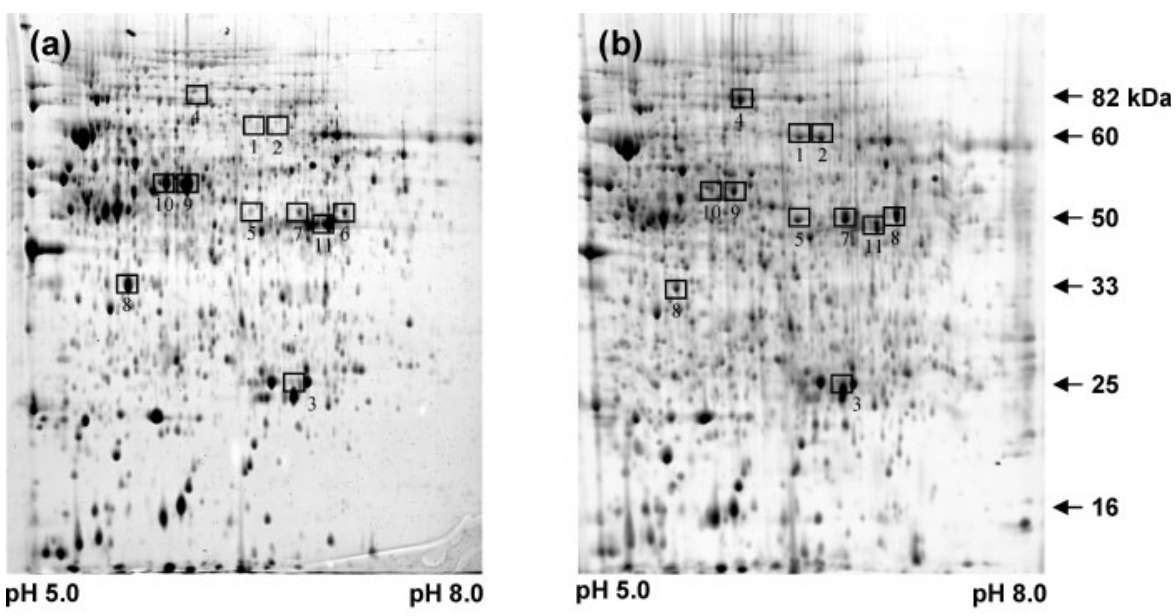

(c)
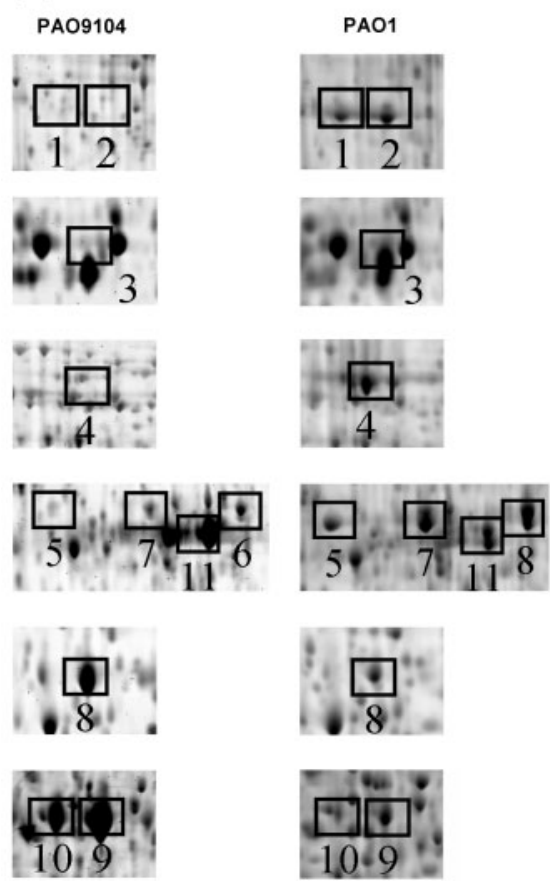

Fig. 1. 2D PAGE of crude cell-free extracts from the $P$. aeruginosa nar $L$ mutant (a) and the PAO1 wild-type strain (b) incubated under anaerobic conditions in LB medium containing $50 \mathrm{mM}$ nitrate. Boxed areas in the gel images with significant changes in protein pattern are shown as enlarged images in (c). Boxed spots with numbers represent proteins that are synthesized at higher or lower amounts in the narL mutant strain. The numbers correspond to the numbers of the protein spots given in Table 2. Two representative gel images from three replicate gels are shown. Proteins were stained with RuBPS (see Methods).

promoter activity is mediated by direct repression of the $\operatorname{arc} D A B C$ promoter via NarL. Earlier investigations showed that the $\operatorname{arcDABC}$ operon is expressed in response to oxygen limitation in an Anr-dependent manner (Galimand et al., 1991) and that the presence of arginine increases transcription via the ArgR regulator (Lu et al., 1999). The $\operatorname{arcDABC}$ promoter region contains an Anrbinding site at $-41.5 \mathrm{nt}$ (Gamper et al., 1991) and an ArgR-binding site, which spans from $-94 \mathrm{nt}$ to $-53 \mathrm{nt}$ relative to the transcriptional start site (Lu et al., 1999). We searched the $\operatorname{arcD}$ promoter for the presence of a NarL-binding site using the Virtual Footprint tool from the PRODORIC database (Münch et al., 2005). This analysis revealed one conserved heptameric NarL-binding site located $-60 \mathrm{nt}$ upstream of the published transcriptional start site shown in Fig. 3 (Gamper et al., 1991). The position of the NarL heptameric binding site at $-60 \mathrm{nt}$ overlaps with the ArgR-binding site and suggests that NarL interferes with ArgR but not with the Anr regulator. In order to functionally confirm the bioinformatics prediction, the putative heptameric NarL-binding site was mutated (TACTCAA $\rightarrow$ CATTCAA) based on the published NarL consensus binding sequence from E. coli $\left(\mathrm{TAC} / \mathrm{T}^{\mathrm{A}} / \mathrm{C}\right.$ ) (Tyson et al., 1993). Since the NarL box partly overlaps with the ArgR box we carefully selected positions for mutagenesis in order to avoid the change of nucleotides known to be important for ArgR binding (see Fig. 3 for details) (Lu et al., 1999). We determined $\beta$ galactosidase activities of strain BB46 containing the mutated $P_{\operatorname{arcD} \Delta \text { NarL-lac }} Z$ fusion in the wild-type strain. The activities of BB46 (1696 MU) were similar to those obtained for the $P_{\text {arcD }}-l a c Z$ in the narL mutant BB45 (1975 $M U)$. This result confirms a direct repression of the $\operatorname{arcDABC}$ promoter via NarL. 
Table 2. Identified proteins differentially synthesized in the $P$. aeruginosa wild-type compared to the narL mutant

\begin{tabular}{|lllll|}
\hline Spot no. & PA no. $\dagger$ & Protein $\dagger$ & \multicolumn{1}{c|}{ Description $\dagger$} & Regulation $¥$ wt vs $\Delta$ narL \\
\hline 1 & PA3874 & NarH & Respiratory nitrate reductase $\beta$ chain & 45.73 \\
2 & PA3874 & NarH & Respiratory nitrate reductase $\beta$ chain & 28.61 \\
3 & PA5496 & CrdJb & Class II ribonucleotide reductase & 12.36 \\
4 & PA5497 & NrdJa & Outer membrane porin OprE & 4.69 \\
5 & PA0291 & OprE & Outer membrane porin OprE & 2.31 \\
6 & OprE & Outer membrane porin OprE & 1.54 \\
7 & PA0291 & OprE & Carbamate kinase & 0.69 \\
8 & PA5173 & ArcC & Arginine deiminase & 0.13 \\
9 & PA5171 & ArcA & Arginine deiminase & 0.09 \\
10 & PA5171 & ArcA & Catabolic ornithine carbomoyltransferase & 0.12 \\
11 & PA5172 & ArcB & & \\
\end{tabular}

${ }^{\star}$ Spot number refers to Fig. 1 .

$\dagger$ PA number, protein short name and description according to the Pseudomonas database (http://www.Pseudomonas.com) (Stover et al., 2000). $\ddagger$ Ratios of protein amount from a $P$. aeruginosa PAO1 wild-type culture to a $P$. aeruginosa narL mutant PAO9104 culture both incubated under anaerobic conditions in LB medium containing $50 \mathrm{mM} \mathrm{KNO}_{3}$.

\section{Arginine-dependent ArgR activation of arcDABC is repressed by nitrate-dependent NarL}

To elucidate whether NarL interferes with the Anr or ArgR regulator at the $\operatorname{arcD}$ promoter, we extended our reporter gene experiments for the separate addition of nitrate and arginine to defined growth medium. The results are given in Table 3. The highest $\beta$-galactosidase activities of the $P_{\mathrm{arcD}}{ }^{-}$ lac $Z$ fusion in the wild-type (BB43) and the narL mutant strain (BB45) were measured for anaerobic conditions in the presence of $20 \mathrm{mM}$ arginine. The addition of nitrate decreased $\beta$-galactosidase activities by $55 \%$ in the wildtype, but by only $24 \%$ or $19 \%$ in the narL mutant strain or the wild-type strain containing the $P_{\operatorname{arcD} \Delta N a r L}-l a c Z$ fusion

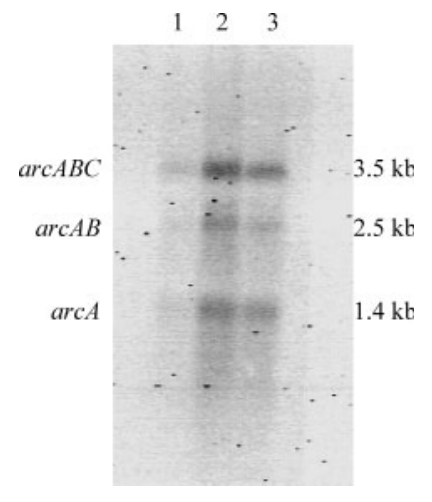

Fig. 2. Northern blot analysis of transcripts from the $\operatorname{arc} D A B C$ operon with RNA prepared from $P$. aeruginosa wild-type PAO1 grown under oxygen limitation in LB medium with $50 \mathrm{mM}$ nitrate (lane 1), the wild-type PAO1 grown without nitrate addition (lane 2) and the $P$. aeruginosa narL mutant PAO9104 incubated in LB medium supplemented with $50 \mathrm{mM}$ nitrate (lane 3). Total RNA $(10 \mu \mathrm{g})$ was isolated after $3 \mathrm{~h}$ incubation at $37^{\circ} \mathrm{C}$. The mRNAs were detected using an $\operatorname{arc} A$-specific probe. with the mutated NarL-binding site in the $\operatorname{arcD}$ promoter region (Table 3). These results clearly show a NarLdependent repression of the arginine-mediated activation of the $\operatorname{arcD}$ promoter via the proposed NarL-binding site.

\section{DISCUSSION}

Three enzymes of the arginine deiminase pathway, ArcA, $\mathrm{ArcB}$ and $\mathrm{ArcC}$, were produced in higher amounts under anaerobic denitrifying conditions in the $P$. aeruginosa narL mutant strain, indicating a repression of the corresponding genes by NarL. It has been shown previously that the specific activity of the catabolic ornithine carbamoyltransferase (ArcB) of the arginine deiminase pathway is repressed by nitrate (Mercenier et al., 1980). However, it was unknown whether this repression was mediated by the NarL regulator itself. Our Northern blot analysis and experiments with $P_{\mathrm{arcD}}-l a c Z$ reporter gene fusions of the PAO1 wild-type and the PAO9104 mutant strains clearly indicated a repression at the transcriptional level.

A bioinformatics analysis of the $\operatorname{arcD}$ promoter region identified a putative heptameric NarL-binding site at $-60 \mathrm{nt}$ to the transcriptional start site. This putative binding site (TACTCAA) differs only in one position from the published E. coli NarL consensus binding sequence $\left(\mathrm{TAC}^{\mathrm{C}} / \mathrm{T}_{\mathrm{T}}^{\mathrm{A}} / \mathrm{C} \mathrm{T}\right.$ ) (Tyson et al., 1993). This putative NarL-binding site overlaps with the binding site of the ArgR regulator, which complicated mutagenesis of the NarL-binding site. However, we carefully selected positions for mutagenesis in order to avoid the change of nucleotides known to be important for ArgR binding (see Fig. 3 for details) (Lu et al., 1999). The consensus sequence of the ArgR-binding site has been deduced from DNase I footprinting studies (Lu et al., 1999, 2004). Control experiments in AB minimal medium with arginine confirmed that the mutation left the ArgRbinding site functional. It showed that $\beta$-galactosidase 
1
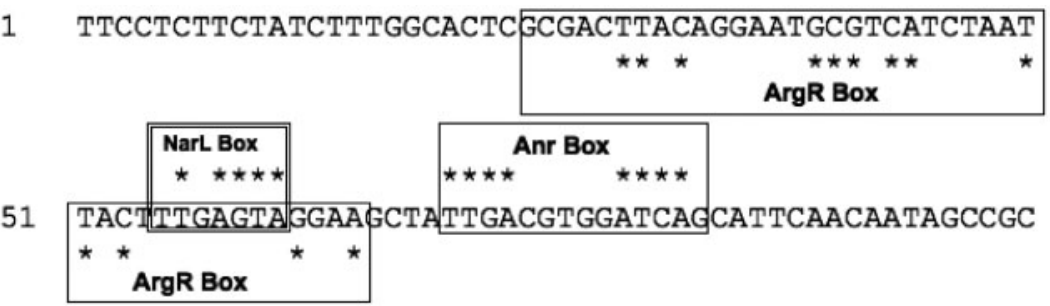

ArgR Box

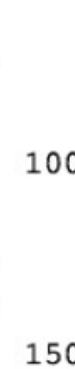

101 TGCCGССTAATGTCTTCACTCTCAATTCCTATAGGGAGATTCCGAAAATG 150

Fig. 3. Nucleotide sequence of the $\operatorname{arc} D A B C$ promoter region. The previously determined transcriptional start site (Galimand et al., 1991), the putative -10 region and the start of the $\operatorname{arc} D$ coding region are marked. Binding sites for the regulatory proteins ArgR, NarL and Anr are boxed. Bases identical to published consensus sequences (Galimand et al., 1991; Lu et al., 1999; Spiro \& Guest, 1990) are marked by an asterisk. Compared to the ArgR box, the orientation of the NarL-binding site is in the opposite direction to the transcriptional start site (TACTCAA). The published consensus sequence used for NarL (Tyson et al., 1993) reads $\mathrm{TAC}^{\mathrm{C}} / \mathrm{T}^{\mathrm{A}} / \mathrm{C} T$ and differs in one position from that detected in the arc promoter.

activities of strain BB45, which carries the reporter gene fusion with the mutated NarL-binding site, increased fivefold in response to arginine compared to the reporter gene fusion with the intact NarL-binding site. The position of the putative NarL-binding site, as well as the results of the reporter gene fusion experiments, suggests the following model. The NarX-NarL regulatory system of $P$. aeruginosa is employed for activation of nitrate respiration and downregulation of arginine fermentation under anaerobic conditions (Fig. 4). However, NarL does not completely abolish the expression of the $\operatorname{arcDABC}$ operon. In the presence of nitrate and arginine, NarL binding most likely prevents interaction of the arginine-dependent ArgR activator with its overlapping binding site and represses the further induction of $\operatorname{arc} D A B C$ transcription by ArgR. No repression of $\operatorname{arcDABC}$ transcription by NarL was observed in the absence of arginine (Table 3). This finding is in agreement with the concept of a double role for NarL as an activator for nitrate reductase formation as well as a repressor of energetically less effective fermentative pathways.

Moreover, our findings are also in agreement with data recently published by Platt et al. (2008). The authors observed expression of the arginine deiminase pathway under anaerobic denitrifying conditions in complex medium containing arginine. Under these conditions NarL prevents additional activation of $\operatorname{arcD} A B C$ via ArgR, but not the basic expression mediated by the Anr regulator.

Our proteomics approach revealed four additional proteins with decreased concentration in the narL mutant strain. Only the corresponding gene of $\mathrm{NarH}$, which is a part of the narK $K_{1} K_{2} G H J I$ operon, has been shown to be under direct control of the NarL regulator (Schreiber et al., 2007). We did not identify any highly conserved NarL-binding sites in the putative promoter regions of the genes for the remaining three proteins (data not shown). Therefore, a direct control via NarL seems unlikely. Moreover, proteins homologous to OprE, NrdJa and NrdJb are not part of the E. coli NarL regulon (Constantinidou et al., 2006).

\section{ACKNOWLEDGEMENTS}

We thank H. P. Schweizer (University of Colorado, USA) for providing the mini-CTX-lacZ and pFLP2 plasmids and Dana Heldt from our laboratory for the construction of pDH11. The investigation was

Table 3. Expression of the $P_{\text {arcD }}-l a c Z$ reporter gene fusions in the $P$. aeruginosa wild-type and the narL mutant

\begin{tabular}{|c|c|c|c|c|c|c|}
\hline \multirow[t]{2}{*}{ P. aeruginosa strain } & \multirow[t]{2}{*}{ lac $Z$ fusion } & \multirow[t]{2}{*}{ Strain background } & \multicolumn{4}{|c|}{$\beta$-Galactosidase activity $(\mathrm{MU})^{\star}$} \\
\hline & & & - & $\begin{array}{c}- \\
+\mathrm{NO}_{3}^{-} \\
\end{array}$ & $\begin{array}{c}+ \text { Arg } \\
-\end{array}$ & $\begin{array}{r}+\mathrm{Arg} \\
+\mathrm{NO}_{3}^{-} \\
\end{array}$ \\
\hline BB43 & $P_{\text {arcD }}$ & PAO1 (wt) & 103 & 92 & 621 & 275 \\
\hline BB45 & $P_{\text {arcD }}$ & PAO9104 ( $\Delta$ narL $)$ & 233 & 305 & 666 & 505 \\
\hline BB46 & $P_{\text {arcD } \Delta \mathrm{NarL}}$ & PAO1 (wt) & 469 & 431 & 2364 & 1916 \\
\hline
\end{tabular}

*Bacteria were grown under oxygen-limited conditions in modified $\mathrm{AB}$ minimal medium. As indicated, $50 \mathrm{mM} \mathrm{KNO}_{3}$ and $20 \mathrm{mM}$ arginine were added. After $7 \mathrm{~h}$ incubation at $37^{\circ} \mathrm{C}$, samples were taken for the $\beta$-galactosidase assay. $\beta$-Galactosidase activities are the mean of at least three independent experiments. Standard deviations ranged between 3 and $15 \%$ of the mean. 


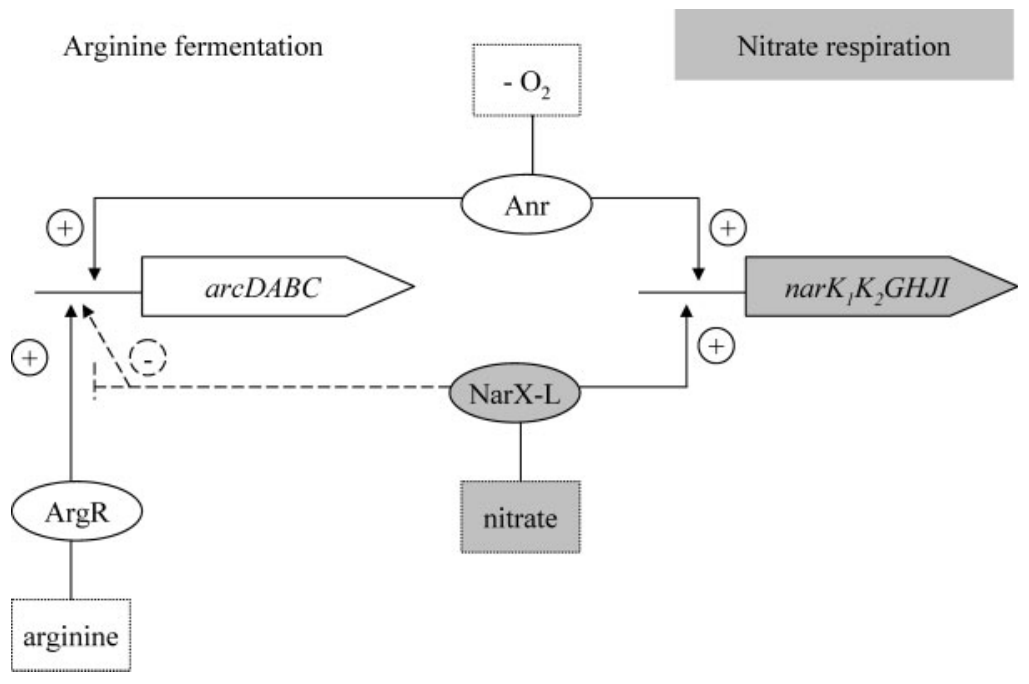

Fig. 4. Schematic representation of NarXNarL-dependent regulation. The major regulator for anaerobic growth is Anr, which activates $\operatorname{arc} D A B C$ even in the absence of arginine and nitrate. In the presence of arginine the $\operatorname{ArgR}$ regulator stimulates transcription of the $\operatorname{arc} D A B C$ operon. If arginine and nitrate are available, the NarL regulator represses the ArgR-dependent arcDABC stimulation by binding to the corresponding promoter region. On the other hand, expression of the nitrate reductase operon $\operatorname{narK}_{1} K_{2} G H J$, which catalyses the first step in denitrification, is induced by the nitrate-response system NarX-NarL.

founded by the Deutsche Forschungsgemeinschaft, the German Research Centre for Biotechnology and the Fonds der Chemischen Industrie. K. S. was supported by the DFG-European Graduate College 653.

\section{REFERENCES}

Arai, H., Kodama, T. \& Igarashi, Y. (1997). Cascade regulation of the two CRP/FNR-related transcriptional regulators (ANR and DNR) and the denitrification enzymes in Pseudomonas aeruginosa. Mol Microbiol 25, 1141-1148.

Arai, H., Kodama, T. \& Igarashi, Y. (1999). Effect of nitrogen oxides on expression of the nir and nor genes for denitrification in Pseudomonas aeruginosa. FEMS Microbiol Lett 170, 19-24.

Arai, H., Mizutani, M. \& Igarashi, Y. (2003). Transcriptional regulation of the nos genes for nitrous oxide reductase in Pseudomonas aeruginosa. Microbiology 149, 29-36.

Barraud, N., Hassett, D. J., Hwang, S. H., Rice, S. A., Kjelleberg, S. \& Webb, J. S. (2006). Involvement of nitric oxide in biofilm dispersal of Pseudomonas aeruginosa. J Bacteriol 188, 7344-7353.

Becher, A. \& Schweizer, H. P. (2000). Integration-proficient Pseudomonas aeruginosa vectors for isolation of single-copy chromosomal lacZ and lux gene fusions. Biotechniques 29, 948-950, 952.

Boes, N., Schreiber, K., Härtig, E., Jaensch, L. \& Schobert, M. (2006). The Pseudomonas aeruginosa universal stress protein PA4352 is essential for surviving anaerobic energy stress. J Bacteriol 188, 6529-6538.

Carlson, C. A. \& Ingraham, J. L. (1983). Comparison of denitrification by Pseudomonas stutzeri, Pseudomonas aeruginosa, and Paracoccus denitrificans. Appl Environ Microbiol 45, 1247-1253.

Chiang, R. C., Cavicchioli, R. \& Gunsalus, R. P. (1992). Identification and characterization of $n a r Q$, a second nitrate sensor for nitratedependent gene regulation in Escherichia coli. Mol Microbiol 6, 1913-1923.

Constantinidou, C., Hobman, J. L., Griffiths, L., Patel, M. D., Penn, C. W., Cole, J. A. \& Overton, T. W. (2006). A reassessment of the FNR regulon and transcriptomic analysis of the effects of nitrate, nitrite, NarXL, and NarQP as Escherichia coli K12 adapts from aerobic to anaerobic growth. J Biol Chem 281, 4802-4815.

de Lorenzo, V. \& Timmis, K. N. (1994). Analysis and construction of stable phenotypes in gram-negative bacteria with Tn5- and Tn10derived minitransposons. Methods Enzymol 235, 386-405.
Dunn, N. W. \& Holloway, B. W. (1971). Pleiotrophy of $p$ fluorophenylalanine-resistant and antibiotic hypersensitive mutants of Pseudomonas aeruginosa. Genet Res 18, 185-197.

Filiatrault, M. J., Picardo, K. F., Ngai, H., Passador, L. \& Iglewski, B. H. (2006). Identification of Pseudomonas aeruginosa genes involved in virulence and anaerobic growth. Infect Immun 74, 4237-4245.

Galimand, M., Gamper, M., Zimmermann, A. \& Haas, D. (1991). Positive FNR-like control of anaerobic arginine degradation and nitrate respiration in Pseudomonas aeruginosa. J Bacteriol 173, 1598-1606.

Gamper, M., Zimmermann, A. \& Haas, D. (1991). Anaerobic regulation of transcription initiation in the $\operatorname{arcDABC}$ operon of Pseudomonas aeruginosa. J Bacteriol 173, 4742-4750.

Gamper, M., Ganter, B., Polito, M. R. \& Haas, D. (1992). RNA processing modulates the expression of the $\operatorname{arcDABC}$ operon in Pseudomonas aeruginosa. J Mol Biol 226, 943-957.

Härtig, E., Schiek, U., Vollack, K. U. \& Zumft, W. G. (1999). Nitrate and nitrite control of respiratory nitrate reduction in denitrifying Pseudomonas stutzeri by a two-component regulatory system homologous to NarXL of Escherichia coli. J Bacteriol 181, 3658-3665.

Hassett, D. J., Cuppoletti, J., Trapnell, B., Lymar, S. V., Rowe, J. J., Yoon, S. S., Hilliard, G. M., Parvatiyar, K., Kamani, M. C. \& other authors (2002). Anaerobic metabolism and quorum sensing by Pseudomonas aeruginosa biofilms in chronically infected cystic fibrosis airways: rethinking antibiotic treatment strategies and drug targets. Adv Drug Deliv Rev 54, 1425-1443.

Heydorn, A., Nielsen, A. T., Hentzer, M., Sternberg, C., Givskov, M., Ersboll, B. K. \& Molin, S. (2000). Quantification of biofilm structures by the novel computer program COMSTAT. Microbiology 146, 23952407.

Ho, S. N., Hunt, H. D., Horton, R. M., Pullen, J. K. \& Pease, L. R. (1989). Site-directed mutagenesis by overlap extension using the polymerase chain reaction. Gene 77, 51-59.

Hoang, T. T., Karkhoff-Schweizer, R. R., Kutchma, A. J. \& Schweizer, H. P. (1998). A broad-host-range Flp-FRT recombination system for site-specific excision of chromosomally-located DNA sequences: application for isolation of unmarked Pseudomonas aeruginosa mutants. Gene 212, 77-86.

Krieger, R., Rompf, A., Schobert, M. \& Jahn, D. (2002). The Pseudomonas aeruginosa hemA promoter is regulated by Anr, Dnr, NarL and Integration Host Factor. Mol Genet Genomics 267, 409-417. 
Lu, C. D., Winteler, H., Abdelal, A. \& Haas, D. (1999). The ArgR regulatory protein, a helper to the anaerobic regulator ANR during transcriptional activation of the $\operatorname{arcD}$ promoter in Pseudomonas aeruginosa. J Bacteriol 181, 2459-2464.

Lu, C. D., Yang, Z. \& Li, W. (2004). Transcriptome analysis of the ArgR regulon in Pseudomonas aeruginosa. J Bacteriol 186, 3855-3861.

Luthi, E., Baur, H., Gamper, M., Brunner, F., Villeval, D., Mercenier, A. \& Haas, D. (1990). The arc operon for anaerobic arginine catabolism in Pseudomonas aeruginosa contains an additional gene, $\operatorname{arcD}$, encoding a membrane protein. Gene 87, 37-43.

Mercenier, A., Simon, J. P., Vander Wauven, C., Haas, D. \& Stalon, V. (1980). Regulation of enzyme synthesis in the arginine deiminase pathway of Pseudomonas aeruginosa. J Bacteriol 144, 159-163.

Münch, R., Hiller, K., Grote, A., Scheer, M., Klein, J., Schobert, M. \& Jahn, D. (2005). Virtual Footprint and PRODORIC: an integrative framework for regulon prediction in prokaryotes. Bioinformatics 21, 4187-4189.

Palmer, K. L., Brown, S. A. \& Whiteley, M. (2007). Membrane-bound nitrate reductase is required for anaerobic growth in cystic fibrosis sputum. J Bacteriol 189, 4449-4455.

Platt, M. D., Schurr, M. J., Sauer, K., Vazquez, G., Kukavica-lbrulj, I., Potvin, E., Levesque, R. C., Fedynak, A., Brinkman, F. S. \& other authors (2008). Proteomic, microarray, and signature-tagged mutagenesis analyses of anaerobic Pseudomonas aeruginosa at $\mathrm{pH}$ 6.5, likely representing chronic, late-stage cystic fibrosis airway conditions. J Bacteriol 190, 2739-2758.

Rabin, R. S. \& Stewart, V. (1993). Dual response regulators (NarL and NarP) interact with dual sensors (NarX and NarQ) to control nitrateand nitrite-regulated gene expression in Escherichia coli K-12. J Bacteriol 175, 3259-3268.

Sauer, K., Camper, A. K., Ehrlich, G. D., Costerton, J. W. \& Davies, D. G. (2002). Pseudomonas aeruginosa displays multiple phenotypes during development as a biofilm. J Bacteriol 184, 1140-1154.

Schreiber, K., Boes, N., Eschbach, M., Jaensch, L., Wehland, J., Bjarnsholt, T., Givskov, M., Hentzer, M. \& Schobert, M. (2006). Anaerobic survival of Pseudomonas aeruginosa by pyruvate fermentation requires an Usp-type stress protein. J Bacteriol 188, 659-668.

Schreiber, K., Krieger, R., Benkert, B., Eschbach, M., Arai, H., Schobert, M. \& Jahn, D. (2007). The anaerobic regulatory network required for Pseudomonas aeruginosa nitrate respiration. J Bacteriol 189, 4310-4314.

Sharma, V., Noriega, C. E. \& Rowe, J. J. (2006). Involvement of NarK1 and NarK2 proteins in transport of nitrate and nitrite in the denitrifying bacterium Pseudomonas aeruginosa PAO1. Appl Environ Microbiol 72, 695-701.

Spiro, S. \& Guest, J. R. (1990). FNR and its role in oxygen-regulated gene expression in Escherichia coli. FEMS Microbiol Rev 6, 399-428.

Stewart, V. (2003). Biochemical Society Special Lecture. Nitrate- and nitrite-responsive sensors NarX and NarQ of proteobacteria. Biochem Soc Trans 31, 1-10.
Stewart, V. \& Rabin, R. S. (1995). Dual sensors and dual response regulators interact to control nitrate- and nitrite-responsive gene expression in Escherichia coli. In Two-Component Signal Transduction, pp. 233-252. Edited by J. A. Hoch \& T. J. Silhavy. Washington, DC: American Society for Microbiology.

Stover, C. K., Pham, X. Q., Erwin, A. L., Mizoguchi, S. D., Warrener, P., Hickey, M. J., Brinkman, F. S., Hufnagle, W. O., Kowalik, D. J. \& other authors (2000). Complete genome sequence of Pseudomonas aeruginosa PAO1, an opportunistic pathogen. Nature 406, 959-964.

Torrents, E., Poplawski, A. \& Sjoberg, B. M. (2005). Two proteins mediate class II ribonucleotide reductase activity in Pseudomonas aeruginosa: expression and transcriptional analysis of the aerobic enzymes. J Biol Chem 280, 16571-16578.

Tyson, K. L., Bell, A. I., Cole, J. A. \& Busby, S. J. (1993). Definition of nitrite and nitrate response elements at the anaerobically inducible Escherichia coli nirB promoter: interactions between FNR and NarL. Mol Microbiol 7, 151-157.

Van Alst, N. E., Picardo, K. F., Iglewski, B. H. \& Haidaris, C. G. (2007). Nitrate sensing and metabolism modulate motility, biofilm formation, and virulence in Pseudomonas aeruginosa. Infect Immun 75, 3780-3790.

Vander Wauven, C., Pierard, A., Kley-Raymann, M. \& Haas, D. (1984). Pseudomonas aeruginosa mutants affected in anaerobic growth on arginine: evidence for a four-gene cluster encoding the arginine deiminase pathway. J Bacteriol 160, 928-934.

Vollack, K. U., Härtig, E., Korner, H. \& Zumft, W. G. (1999). Multiple transcription factors of the FNR family in denitrifying Pseudomonas stutzeri: characterization of four fnr-like genes, regulatory responses and cognate metabolic processes. Mol Microbiol 31, 1681-1694.

Worlitzsch, D., Tarran, R., Ulrich, M., Schwab, U., Cekici, A., Meyer, K. C., Birrer, P., Bellon, G., Berger, J. \& other authors (2002). Effects of reduced mucus oxygen concentration in airway Pseudomonas infections of cystic fibrosis patients. J Clin Invest 109, 317-325.

Xu, K. D., Stewart, P. S., Xia, F., Huang, C. T. \& McFeters, G. A. (1998). Spatial physiological heterogeneity in Pseudomonas aeruginosa biofilm is determined by oxygen availability. Appl Environ Microbiol 64, 4035-4039.

Yamano, Y., Nishikawa, T. \& Komatsu, Y. (1993). Cloning and nucleotide sequence of anaerobically induced porin protein E1 (OprE) of Pseudomonas aeruginosa PAO1. Mol Microbiol 8, 993-1004.

Ye, R. W., Haas, D., Ka, J. O., Krishnapillai, V., Zimmermann, A., Baird, C. \& Tiedje, J. M. (1995). Anaerobic activation of the entire denitrification pathway in Pseudomonas aeruginosa requires Anr, an analog of Fnr. J Bacteriol 177, 3606-3609.

Zumft, W. G. (1997). Cell biology and molecular basis of denitrification. Microbiol Mol Biol Rev 61, 533-616.

Edited by: M. A. Kertesz 